\title{
Understanding the Rare Krukenberg Tumor: A Current Review
}

\author{
Emmanouil Charakopoulos, Nikolaos Thomakos, Dafni Sourelli, \\ Konstantinos Sideris, Alexandros Rodolakis
}

1st Department of Obstetrics and Gynecology, "Alexandra" Maternity Hospital, National and Kapodistrian University of Athens, Athens, Greece

\section{Correspondence}

NikolaosThomakos, Department of Obstetrics and Gynecology, "Alexandra" Maternity Hospital, National and Kapodistrian University of Athens, Athens, Greece, e-mail: thomakir@hotmail.com

\section{Abstract}

Krukenberg tumors represent a rare type of secondary ovarian tumors composed of mucinous signetring cells. In up to $70 \%$ of cases the primary site is a diffuse type gastric carcinoma, which disseminates to the ovary through a retrograde lymphatic pathway.The Krukenberg tumor is a good example of metastatic ovarian organotropism ("seed and soil" hypothesis).The symptoms are nonspecific and usually don't develop until the tumors reach a certain size. The definitive diagnosis can only be made histologically after surgical resection, although imaging findings can indirectly aid in the distinction between benign-malignant and primary-secondary tumors. Immunohistochemistry is the most important diagnostic method in distinguishing primary from secondary ovarian neoplasms, and can usually detect the tissue of origin. The extremely dismal prognosis of Krukenberg tumors is attributed to the fact that they represent an advanced stage metastatic disease. Although the standard treatment is systemic chemotherapydepending on the primary site, there are rough indications that cytoreductive surgery might prolong survival in selected patients.

Key words: krukenberg tumor, ovarian metastasis, secondary ovarian tumor, gastric cancer, signet-ring cells

\section{Introduction}

To begin with, the first who stated the idea of the existence of tumors that tend to metastasize to secondary sites that are not related anatomically or vascularly was Paget back in $1889^{1}$. During the next decade, a German gynecologist and pathologist, named Friedrich Ernst Krukenberg (1871-1946), described a presumably new type of primary ovarian tumor ${ }^{2}$. Krukenberg's experiments showed that this tumor had some significant clinicopathologicalcharacteristics, more specifically ascites and bilateral appearance. Under the microscope, Krukenberg observed the pathognomonic signet-ring cells, which are formed by mucin that pushes the nucleus of the cell on one side. Besides signet-ring cells, these tumors were characterized by solid areas alternating 
with myxomatous zones with dominant lymphatic involvement ${ }^{3}$. Krukenberg named these tumors as "brosarcomaovariimucocellularecarcinomatodes"1. The first who used the term Krukenberg tumor (KT) seems to be Kraus five years later, who also showed that these tumors were secondary and not primary4. However, most articles in the literature report that Schlagenhaufer, and not Kraus, made this discovery six years later ${ }^{3}$.

Nowadays, KTs are defined as secondary tumors of the ovaries (STOs) that histopathologically appear as carcinomas that have a significant component (arbitrarily $>10 \%$ ) of mucin-producingsignet-ring cells ${ }^{5.7}$. The most commonly noticed primary site of KTs is gastric cancer (70\%), especially the poorly cohesive signet-ring cell type (8), followed by the colorectal tract (10\%) and the breast (5\%). Other rare sites include: biliary tract and gallbladder, small intestine, appendix, pancreas, uterus, bladder, kidney ${ }^{7}$.

\section{Epidemiology}

In general, ovarian metastases represent 15-30\% of all ovarian tumors and KTs make up about 10\% of all ovarian metastases. In more detail, the proportion of non-gynecologic malignancies is estimated to be as high as $60-80 \%$ of all STOs (gastrointestinal tract metastases $35-50 \%$ and breast metastases 15$30 \%$ ), whereas the percentagefor gynecologic primary tumors is only $20-40 \%{ }^{9-11}$. KTs also own the first place in the category of the most common bilateral metastatic tumor of the ovaries, as they are reported to be bilateral in $70-80 \%$ of all cases ${ }^{7.12,13}$.

One more important thing that has to be mentioned is the geographic distribution. For example, Asian Countries have a much higher incidence of STOs compared to European countries. This phenomenon can be easily explained if we study the epidemiology of the main cause of KTs, which is gastric cancer. Countries such as Japan and Korea have a much higher incidence of signet-ring cell gastric cancer compared to European countries, resulting in higher prevalence of KTs in these regions ${ }^{14.15}$.

A second important factor that is worth mentioning is the age in which KTs are diagnosed. Mean age is about 45 years,and $40 \%$ of patients are under 40 years old ${ }^{7}$. Studies have shown that patients with primary tumors in the gastrointestinal (GI) tract represent the oldest group, while patients with breast cancer the youngest $\mathrm{t}^{10}$. Interestingly, KTs commonly appear during pregnancy ${ }^{7}$.

Last but not least, two major factors that play a great role in the variability of the incidence of KTs are the laboratory methods used in establishing the diagnosis and the experience of the pathologist ${ }^{16}$.

\section{Pathogenesis}

\section{Route of metastasis}

The exact mechanism of ovarian spread of signetring cell tumors is currently unknown ${ }^{17}$. Considering the fact that KTs represent a metastatic disease that is manifested at a relatively young age ${ }^{8}$ and that gastric neoplasms can metastasize to the ovaries without involvement of other organs ${ }^{18}$, the underlying pathophysiology could be a subject of considerable research interest.

There are three possible mechanisms of spreading: lymphogenous, hematogenous and transcoelomic (across the peritoneal cavity) ${ }^{19}$. The most likely pathway for gastric cancer is the retrograde lymphatic spread $^{20}$. First, cancer cells reach the gastric nodes after having infiltrated the mucosal and submucosal lymphatic vessels of the stomach. This process can happen even during the early stages of gastric can$\operatorname{cer}^{21}$. The distance between the receptaculumchyli and the gastric nodes is short. For that reason, cancer cells can easily reach the receptaculumchyli and then the ovaries through the lumbar trunks ${ }^{20}$. Another mechanism that contributes to the lymphogenic pathway is that cancer cells form emboli, causing obstruc- 
tion of lymph vessels and inhibition of upward flow. This causes lymph to flow backwards to the ovary ${ }^{22}$. In the case of colorectal and breast cancer, hematogenous spread is the most likely pathway ${ }^{8.23}$. This can partially explain the high incidence of KTs in premenopausal women, who have a greater ovarian vascularity ${ }^{24}$. Although a lot of oncologists and surgeons consider KTs as peritoneal deposits, this is in fact the least possible theory ${ }^{8}$.

\section{Ovarianorganotropism}

Metastatic organotropism is defined as the tendency of tumors to metastasize preferentially to specific organs ${ }^{25}$. The basic principle of organotropism is that molecular properties of the primary tumor allow the cancer cells to survive better in the microenvironment of the secondary site ${ }^{26}$. This research field is largely unexplored. In the case of KTs, E-cadherin down-regulation has been proposed as a possible mechanism to explain the ovarian organotropism of these tumors ${ }^{27}$.

\section{Signs and symptoms}

KTs are asymptomatic until they reach a certain $\operatorname{size}^{28}$. The most common symptoms are abdominal pain and distention ${ }^{29}$. Interestingly, KTs can cause luteinization of the ovarian stroma and subsequent production of estrogen, progesterone and androgens. These hormonal changes can provoke vaginal bleeding, disturbances of menstrual habits ${ }^{7}$ and, rarely, virilism ${ }^{30}$. Ascites is present in about $50 \%$ of cases and is associated with a poor prognosis ${ }^{8}$. Occasionally, patients with KTs are presented with nonspecific symptoms, like dyspepsia and weight loss ${ }^{5.7 .10 .31}$. Finally, extremely rare, but interesting manifestations of KTs are pseudomyxomaperitonei (mucin ascites), especially if the primary site is the appendix ${ }^{22}$, and pseudo-Meigs syndrome (triad: KT, ascites, right hydrothorax) ${ }^{32}$.

\section{Diagnosis}

The final diagnosis of KT is histological and is currently based on the diagnostic criteria of the World Health Organization (WHO). For setting the diagnosis, the following criteria have to be fulfilled: (1) Stromal involvement (2) Mucin-producing neoplastic signet-ring cells (3) Ovarian stromal sarcomatoid proliferation $^{33}$.The patient's history, laboratory and imaging tests contribute to the diagnostic procedure. History of gastric cancer can raise suspicion for a metastatic tumor. ${ }^{34}$.

KTs are in most cases (about 70\%) diagnosed before the primary tumor, but they can be diagnosed during staging (synchronous presentation) or after surgical removal of the primary neoplasm (metachronous presentation) ${ }^{7}$.

\section{Ca-125}

The Ca-125 marker is usually elevated, as in about $80 \%$ of the cases of primary epithelial ovarian tumors $^{10,35}$. Ca-125 levels can mainly be used: (1) As a prognostic factor (2) For post-operative follow-up (3) For early detection of KTs in patients with known GIadenocarcinoma ${ }^{36,37}$.

\section{Imaging}

Imaging methods including computed tomography(CT), ultrasonography (US), and magnetic resonance imaging (MRI) exhibit large bilateral ovarian masses (in nearly $80 \%$ of cases), usually solid but sometimes cystic with solid areas. USshowshyperechoic masses, which sometimes exhibit a characteristic for KTs feature called the "lead vessel sign"(38-40).CT shows bilateralfirm masses with homogeneous enhancement. On MRI with T1 and T2 weighted images, regions of the tumor with desmoplastic reaction are hypointense, whereas mucinous regions are hyperintense ${ }^{41,42}$.

Bilateral appearance should always raise suspicion for a metastatic ovarian tumor. It is important 
to know that none of the routinely used imaging modalities has proved to be precise enough in differentiating primary ovarian tumors from secondary ones $^{43,44}$. Imaging might, in some cases, reveal the primary origin as well.

\section{Macroscopic features}

The characteristic gross morphology of KTs is bilateral asymmetrical ovarian masses. Their color is typically white or yellow, and their surface is solid and smooth. The ovarian surface is usually intact ${ }^{12,45,47}$.

\section{Microscopic features}

The microscopic features of KTs can be observed with hematoxylin and eosin stain. KTs have an epithelial and a stromal component. The epithelial component consists of mucin-producing signet-ring cells with eccentric nuclei. Different morphological variants of these cells can appear in the same tumor. When there is dominance of the tubular pattern, the tumor is referred to as tubular KT, a subtype that is worth mentioning because of its different differential diagnosis ${ }^{48}$. Edema,sarcomatoid proliferation and desmoplastic reaction are the main characteristics of the stroma. Sometimes the desmoplastic reaction can be so pronounced that the signet-ring cells cannot be seen clearly and there can be a diagnostic confusion with tumors such as fibromas ${ }^{12,45-47}$.

Signet-ring cells stain with mucin stains (Mayer mucicarmine, acid-Schiff with diastase digestion and Alcian blue) because of their intracellular mucinous material.Immunohistochemically, the tumor cells are positive for epithelial markers, such as cytokeratins (mainly CK20), but they are vimentin and inhibin negative $^{36}$.

\section{Differential diagnosis}

The differential diagnosis from other primary and secondary ovarian tumors is based on the characteristic microscopical features of KTs as set by WHO.
Sometimes the differential diagnosis can be difficult. The contribution of immunohistochemistry (IHC) is significant.

\section{Histological Differential Diagnosis}

The differential diagnosis has to be made between KTs and other ovarian tumors with signet-ring cells,containing mucinous or non-mucinous material. Rarely, it has to be made from tumors without signet-ring cells.Ovarian tumors with signet-ring cells containing mucin include primary mucinous carcinoma and mucinous carcinoid tumors, mainly from the appendix. Ovarian tumors with signet-ring cells without mucin include signet-ring stromal tumor, sclerosing stromal cell tumor, and clear cell adenocarcinoma of the ovary ${ }^{8}$.In the case of tubular KTs, the differential diagnosis has to be made from ovarian tumors with lobular pattern, mainly SertoliLeydig cell tumors ${ }^{7,8}$, especially when KTs occur during pregnancy ${ }^{49}$. Finally, when signet-ring cells present sporadically, KTs can sometimes be confused with fibromas ${ }^{50}$.

\section{Immunohistochemistry}

IHC plays an important role in the differential diagnosis between primary and secondary ovarian tumors.In the caseof metastatic tumors, it can also be used to identify their primary origin. Cytokeratin 7 and 20 (CK7 and CK20) are the most commonly used antigens in ovarian neoplasms. Generally, a CK7+/CK20-immunophenotype is more typical of a primary ovarian carcinoma, whereas a CK7-/CK20+ or CK7+/CK20+ immunophenotype is an indicator of a metastatic ovarian tumor, usually from the GI tract $^{51-53}$.

\section{Prognosis}

Prognosis of KT is extremely worse compared to primary ovarian cancer ${ }^{54}$. The majority of patients with KTs die within 2 years and the median survival 
is 14 months ${ }^{55}$.

\section{Prognostic factors}

To date, the factors that influence the prognosis have not been well defined. This is attributed to the absence of prospective studies, contradictory results and the fact that most relevant studies explore the prognosis of STOs in general, without focusing on the strict definition of $\mathrm{KTs}^{19}$.

Several studies support the hypothesis that an unknown primary site is correlated with a worse prognosis, whereas patients with metachronous presentation have a higher survival rate ${ }^{28}$. Additional favorable prognostic factors include: unilateral $\mathrm{KT}^{56}$, absence of distant metastases, limited extent of the tumor and R0 resection ${ }^{57,58}$. Furthermore, primary breast cancer is associated with the longest survival, followed by tumors originating in the colon, while patients with primary gastric cancer exhibit the poorest overall survival. The most important clinical finding that foreshadows a dismal prognosis is ascites $^{59}$. Finally, preoperative levels of serum CA 125 greater than $75 \mathrm{U} / \mathrm{ml}$ have been related to a worse outcome ${ }^{28}$.

Other factors that have been found to influence the survival rate of patients with STOs in general include: age at diagnosis, pre-operative size ${ }^{28}$ and presence of peritoneal dissemination ${ }^{24}$. Finally, gene expression profiling (GEP) could be of great importance for the prognostic evaluation of patients with $\mathrm{KT}^{60}$.

\section{Treatment}

Currently there is no optimal treatment strategy for $\mathrm{KTs}^{8}$. KTs represent metastatic disease and thus the routine treatment is chemotherapy depending on the primary tumor ${ }^{61}$.

Cytoreductive surgery

The role of cytoreductive surgery in the treatment of STOs is still under debate. Most studies come to the conclusion that optimal debulking prolongs overall survival. Nevertheless, the aforementioned studies are all retrospective, which are often characterized by sampling bias ${ }^{17}$ and provide a lower level of evidence compared to prospective studies and randomized trials $^{62}$.

According to the current literature, it is reasonable to offer surgical treatment to patients with the following characteristics: young age, good performance status, no distant metastases, feasibility of complete resection and primary colorectal cancer. Cases of gastric origin should be individualized taking into account the fact that patients with metachronous presentation might benefit more from a surgical approach compared to patients with synchronous metastases $^{17}$.

In symptomatic patients, palliative surgery should be considered in order to improve quality of life, although chemotherapy could also be applied. Nonetheless, signet-ring cell cancers are characterized by a poor response to chemotherapy. Therefore, surgery is probably the best option for palliative treatment ${ }^{19}$.

\section{Adjuvant chemotherapy}

The results of studies regarding the impact of adjuvant chemotherapy on survival are contradictory $55,63,64$. However, the majority of the studies support the hypothesis that the administration of systemic chemotherapy after surgery seems to prolong overall survival ${ }^{15.65,66}$. Adjuvant chemotherapy in the case of gastric cancer should be platinum-based, whereas the recommended combination for colorectal cancer is 5 -FU/LV with oxaliplatin ${ }^{67,70}$.

\section{Prophylactic oophorectomy}

At the time of primary GI cancer surgery some surgeons perform prophylactic oophorectomy in order to remove or preventpossible ovarian metastases ${ }^{71}$. 
However, the majority of women with GI cancer will not develop KTs. Furthermore, oophorectomy can cause long-term harmful consequences, including cardiovascular disease, cognitive impairment, psychiatric disease and osteoporosis. Consequently,prophylactic oophorectomy should not be routinely performed ${ }^{72}$.

Oophorectomy should also be considered in case of suspicious visual or palpable ovarian findings while performing surgery for GI cancers. For that reason, it is recommended that general surgeons should perform a thorough examination of the pelvic organs during surgery for gastric, colorectal or appendiceal cancers ${ }^{73}$

\section{KT with unknown primary}

In about $10-15 \%$ of cases the primary tumor cannot be detected despite a thorough diagnostic workup $^{13,15}$. A basic routine diagnostic evaluation includes: medical history and physical examination, basic blood and biochemistry analysis, CT scans of thorax, abdomen and pelvis and mammography. Endoscopies should be performed only if there are signs, symptoms or laboratory findings that indicate the presence of cancer in a specific location ${ }^{74}$.

A possible primary tumor site can be presumed by two laboratory methods: IHC and GEP ${ }^{75-77}$ For example, CK20+ CDX2+ and CK7- is the characteristic staining of colorectal cancer ${ }^{74}$.

Cancers of unknown primary site (CUPs) have generally a poor prognosis, although there is a subset of patients who have a more favorable overall survival. These subsets are strictly defined, and, among others, includeCUPs with a colorectal IHC or GEP and single metastatic deposits ${ }^{74}$.

According to ESMO guidelines regarding $\mathrm{CUPs}^{74}$, when the origin of a KT remains occult,unilaterality without any other metastatic deposits and/ora colorectal molecular profile or immunophenotyperepresent an indication for site-specific chemotherapy (similarly to patients with known metastatic primary tumors). In any other case, the recommended treatment is low-toxicity empirical chemotherapy.

\section{Conclusion}

KTs represent rare secondary ovarian tumors and are characterized by a largely unexplored pathophysiology. The term "Krukenberg tumor" should not be used to describe all metastatic ovarian tumors, because KTs exhibit characteristic histological criteria. There is currently no optimal management strategy, due to the lack of prospective studies. The role of cytoreductive surgery in prolonging survival is still under debate. However, KTs represent an advanced stage of the disease and have in general a dismal prognosis regardless of the treatment strategy.

\section{References}

1. Paget $\mathrm{S}$. The distribution of secondary growths in cancer of the breast. 1889. Cancer metastasis reviews. 1989;8(2):98-101.

2. Krukenberg FE. Über Das Fibrosarcoma ovarii mucocellulare (carcinomatodes). . Arch Gynäkol. 1896;50:287-321.

3. Schlagenhaufer F. Ueber das metastatische Ovarialcarcinom nach Krebs des Magens, Darmes und anderer Bauchorgane (Part 1 of 2). Gynecol Obstet Invest 1902;15(4):485-506.

4. Kraus E. Über das zustandekommen der krebsmetastasen im ovarium bei primärem kerbs eines anderen bauchorgans. Monatsschr Geburtsh Gynakol 1901;14:1-30.

5. Young RH. From krukenberg to today: the ever present problems posed by metastatic tumors in the ovary: part I. Historical perspective, general principles, mucinous tumors including the krukenberg tumor. Advances in anatomic pathology. 2006;13(5):205-27.

6. Woodruff JD, Novak ER. The Krukenberg tumor: study of 48 cases from the ovarian tumor reg- 
istry. . Obstetrics and gynecology international. 1960;15:351-60.

7. Kiyokawa T, Young RH, Scully RE. Krukenberg tumors of the ovary: a clinicopathologic analysis of 120 cases with emphasis on their variable pathologic manifestations. The American journal of surgical pathology. 2006;30(3):277-99.

8. Al-Agha OM, Nicastri AD. An in-depth look at Krukenberg tumor: an overview. Archives of pathology \& laboratory medicine. 2006;130 (11):1725-30.

9. Webb MJ, Decker DG, Mussey E. Cancer metastatic to the ovary: factors influencing survival. Obstetrics and gynecology. 1975;45(4):391-6.

10. de Waal YR, Thomas CM, Oei AL, Sweep FC, Massuger LF. Secondary ovarian malignancies: frequency, origin, and characteristics. International journal of gynecological cancer : official journal of the International Gynecological Cancer Society. 2009;19(7):1160-5.

11. Yada-Hashimoto N, Yamamoto T, Kamiura $S$, Seino H, Ohira H, Sawai K, et al. Metastatic ovarian tumors: a review of 64 cases. Gynecologic oncology. 2003;89(2):314-7.

12. Hale RW. Krukenberg tumor of the ovaries. A review of 81 records. Obstetrics and gynecology. 1968;32(2):221-5.

13. Leffel JM, Masson JC, Dockerty MB. Krukenberg's Tumors: A Survey of Forty-Four Cases. Annals of surgery. 1942;115(1):102-13.

14. Lee SJ, Bae JH, Lee AW, Tong SY, Park YG, Park JS. Clinical characteristics of metastatic tumors to the ovaries. Journal of Korean medical science. 2009;24(1):114-9.

15. Kim WY, Kim TJ, Kim SE, Lee JW, Lee JH, Kim BG, et al. The role of cytoreductive surgery for nongenital tract metastatic tumors to the ovaries. European journal of obstetrics, gynecology, and reproductive biology. 2010;149(1):97-101.

16. Kondi-Pafiti A, Kairi-Vasilatou E, Iavazzo C, Das- tamani C, Bakalianou K, Liapis A, et al. Metastatic neoplasms of the ovaries: a clinicopathological study of 97 cases. Archives of gynecology and obstetrics. 2011;284(5):1283-8.

17. Kubecek O, Laco J, Spacek J, Petera J, Kopecky J, Kubeckova A, et al. The pathogenesis, diagnosis, and management of metastatic tumors to the ovary: a comprehensive review. Clinical \& experimental metastasis. 2017;34(5):295-307.

18. Willis RA. The Spread of Tumours in the Human Body. 3rd ed: Butterworths; 1973.

19. Agnes A, Biondi A, Ricci R, Gallotta V, D'Ugo D, Persiani R. Krukenberg tumors: Seed, route and soil. Surgical oncology. 2017;26(4):438-45.

20. Yamanishi Y, Koshiyama M, Ohnaka M, Ueda M, Ukita S, Hishikawa K, et al. Pathways of metastases from primary organs to the ovaries. Obstetrics and gynecology international. 2011;2011: 612817.

21. Kakushima N, Kamoshida T, Hirai S, Hotta S, Hirayama T, Yamada J, et al. Early gastric cancer with Krukenberg tumor and review of cases of intramucosal gastric cancers with Krukenberg tumor. Journal of gastroenterology. 2003;38 (12):1176-80.

22. Asbun HJ, Hughes KS. Management of recurrent and metastatic colorectal carcinoma. Surg Clin North Am. 1993;73(1):145-6.

23. Moore RG, Chung M, Granai CO, Gajewski W, Steinhoff MM. Incidence of metastasis to the ovaries from nongenital tract primary tumors. Gynecologic oncology. 2004;93(1):87-91.

24. Miller BE, Pittman B, Wan JY, Fleming M. Colon cancer with metastasis to the ovary at time of initial diagnosis. Gynecologic oncology. 1997;66 (3):368-71.

25. Kall SL, Koblinski JE. Genes that mediate metastasis organotropism. . Metastatic cancer: clinical and biological perspectives Landes Bioscience; 2013. 
26. Lorusso G, Ruegg C. New insights into the mechanisms of organ-specific breast cancer metastasis. Seminars in cancer biology. 2012;22(3): 226-33.

27. Kuwabara Y, Yamada T, Yamazaki K, Du WL Banno K, Aoki D, et al. Establishment of an Ovarian Metastasis Model and Possible Involvement of E-Cadherin Down-Regulation in the Metastasis. Cancer Science. 2008;99:1933-9.

28. Kikkawa F, Shibata K, Ino K, Nomura S, Kajiyama $\mathrm{H}$, Suzuki T, et al. Preoperative findings in nongynecologic carcinomas metastasizing to the ovaries. . Gynecol Obstet Invest. 2002;54(4):221-7.

29. de Palma P, Wronski M, Bifernino V, Bovani I. Krukenberg tumor in pregnancy with virilization. A case report. European journal of gynaecological oncology. 1995;16(1):59-64.

30. Papakonstantinou E, Liapis A, Kairi-Vassilatou E, Iavazzo C, Kleanthis CK, Kondi-Pafiti A. Virilizing ovarian Krukenberg tumor in a 27-year-old pregnant woman. A case report and literature review. European journal of gynaecological oncology. 2011;32(3):331-3.

31. Fujiwara K, Ohishi Y, Koike H, Sawada S, Moriya T, Kohno I. Clinical implications of metastases to the ovary. Gynecologic oncology. 1995;59(1): 124-8.

32. Cetin B, Aslan S, Akinci M, Atalay C, Cetin A. A long surviving case of Pseudomeigs' syndrome caused by Krukenberg tumor of the stomach. Japanese journal of clinical oncology. 2005;35(4):221-3.

33. Serov SF, Scully RE. Histological typing of ovarian tumors. In: International Histological Classification of Tumours. . WHO, Geneva. 1973;9.

34. Tavassoli FA, Devilee P. Pathology and Genetics of Tumours of the Breast and Female Genital Organs.: IARC; 2003.

35. Pepin K, del Carmen M, Brown A, Dizon DS. CA 125 and epithelial ovarian cancer: role in screening, diagnosis, and surveillance. . Am J Hematol
Oncol 2014;10(6):22-9.

36. Wong PC, Ferenczy A, Fan LD, McCaughey E. Krukenberg tumors of the ovary. Ultrastructural, histochemical and immunohistochemical studies of 15 cases. Cancer. 1986;57(4):751-60.

37. Sugimoto Y, Endo K, Sakahara H, Nakajima K, Abe $\mathrm{M}$, Torizuka K, et al. [Sequential measurement of serum CA 125 levels in Krukenberg's tumor]. Gan no rinsho Japan journal of cancer clinics. 1985;31(15):1893-7.

38. Testa AC, Ferrandina G, Timmerman D, Savelli L, Ludovisi M, Van Holsbeke C, et al. Imaging in gynecological disease (1): ultrasound features of metastases in the ovaries differ depending on the origin of the primary tumor. Ultrasound in obstetrics \& gynecology : the official journal of the International Society of Ultrasound in Obstetrics and Gynecology. 2007;29(5):505-11.

39. Testa AC, Licameli A, Di Legge A, Mascilini F, Petruzziello L, Pelagalli M, et al. Color Doppler sonographic features of a Krukenberg tumor in pregnancy. Journal of ultrasound in medicine : official journal of the American Institute of Ultrasound in Medicine. 2009;28(5):695-8.

40. Cho JY, Seong CK, Kim SH. Krukenberg tumor findings at color and power Doppler US; correlation with findings at CT, MR imaging, and pathology. Case reports. Acta radiologica. 1998;39(3): 327-9.

41. Choi HJ, Lee JH, Kang S, Seo SS, Choi JI, Lee S, et al. Contrast-enhanced CT for differentiation of ovarian metastasis from gastrointestinal tract cancer: stomach cancer versus colon cancer. AJR American journal of roentgenology. 2006;187(3): 741-5.

42. Jung SE, Lee JM, Rha SE, Byun JY, Jung JI, Hahn ST. CT and MR imaging of ovarian tumors with emphasis on differential diagnosis. Radiographics : a review publication of the Radiological Society of North America, Inc. 2002;22(6):1305-25. 
43. Brown DL, Zou KH, Tempany CM, Frates MC, Silverman SG, McNeil BJ, et al. Primary versus secondary ovarian malignancy: imaging findings of adnexal masses in the Radiology Diagnostic Oncology Group Study. Radiology. 2001;219(1): 213-8.

44. Willmott F, Allouni KA, Rockall A. Radiological manifestations of metastasis to the ovary. Journal of clinical pathology. 2012;65(7):585-90.

45. Holtz F, Hart WR. Krukenberg tumors of the ovary: a clinicopathologic analysis of 27 cases. Cancer. 1982;50(11):2438-47.

46. Duarte I, Llanos O. Patterns of metastases in intestinal and diffuse types of carcinoma of the stomach. Human pathology. 1981;12(3):237-42.

47. Rosai J. Rosai and Ackerman's Surgical Pathology. 9th ed. St Louis: Mo: The CV Mosby Co; 2004.

48. Fung MF, Vadas G, Lotocki $R$, Heywood $M$, Krepart G. Tubular Krukenberg tumor in pregnancy with virilization. Gynecologic oncology. 1991;41(1):81-4.

49. Young RH. Ovarian tumors and tumor-like lesions in the first three decades. Seminars in diagnostic pathology. 2014;31(5):382-426.

50. Miyashita Y. Studies on gastric carcinoma: the mechanism of its metastasis to ovaries. Nihon Ganchiryo Gakukai Shi J Jpn Cancer Th. 1969;4:469-81.

51. Park SY, Kim HS, Hong EK, Kim WH. Expression of cytokeratins 7 and 20 in primary carcinomas of the stomach and colorectum and their value in the differential diagnosis of metastatic carcinomas to the ovary. Human pathology. 2002;33(11):1078-85.

52. Wauters CC, Smedts F, Gerrits LG, Bosman FT, Ramaekers FC. Keratins 7 and 20 as diagnostic markers of carcinomas metastatic to the ovary. Human pathology. 1995;26(8):852-5.

53. Ronnett BM, Kurman RJ, Shmookler BM, Sugarbaker PH, Young RH. The morphologic spectrum of ovarian metastases of appendiceal adenocarcinomas: a clinicopathologic and immunohistochemical analysis of tumors often misinterpreted as primary ovarian tumors or metastatic tumors from other gastrointestinal sites. The American journal of surgical pathology. 1997;21(10):114455.

54. Chandradas D, Thomas B, A. J. Diagnosing and treating Krukenberg tumor: a gynecologist's dilemma. Int J Reprod Contracept Obstet Gynecol. 2015;4:2069-71.

55. Benaaboud I, Ghazli M, Kerroumi M, Mansouri A. [Krukenberg tumor: 9 cases report]. Journal de gynecologie, obstetrique et biologie de la reproduction. 2002;31(4):365-70.

56. Schwartz PE. What is the role of neoadjuvant chemotherapy in the management of ovarian cancer? . Oncology (Williston Park). 2008;22:1118-25.

57. Cheong JH, Hyung WJ, Chen J, Kim J, Choi SH, Noh $\mathrm{SH}$. Survival benefit of metastasectomy for Krukenberg tumors from gastric cancer. Gynecologic oncology. 2004;94(2):477-82.

58. Kim HK, Heo DS, Bang YJ, Kim NK. Prognostic factors of Krukenberg's tumor. Gynecologic oncology. 2001;82(1):105-9.

59. Wu F, Zhao X, Mi B, Feng LU, Yuan NA, Lei F, et al. Clinical characteristics and prognostic analysis of Krukenberg tumor. Molecular and clinical oncology. 2015;3(6):1323-8.

60. Ganesh K, Shah RH, Vakiani E, Nash GM, Skottowe HP, Yaeger R, et al. Clinical and genetic determinants of ovarian metastases from colorectal cancer. Cancer. 2017;123(7):1134-43.

61. Ettinger DS, Agulnik M, Cates JM, Cristea M, Denlinger CS, Eaton KD, et al. NCCN Clinical Practice Guidelines Occult primary. Journal of the National Comprehensive Cancer Network : JNCCN. 2011;9(12):1358-95.

62. Dykewicz CA, Centers for Disease C, Prevention, Infectious Diseases Society of A, American Soci- 
ety of B, Marrow T. Summary of the Guidelines for Preventing Opportunistic Infections among Hematopoietic Stem Cell Transplant Recipients. Clinical infectious diseases : an official publication of the Infectious Diseases Society of America. 2001;33(2):139-44.

63. Mrad K, Morice P, Fabre A, Pautier P, Lhomme C, Duvillard P, et al. Krukenberg tumor: a clinicopathological study of 15 cases. Annales de pathologie. 2000;20(3):202-6.

64. Lu W, Yuan L, Liu X, Guo SW. Identification of prognostic factors for Krukenberg tumor. Gynecology and Minimally Invasive Therapy 2013;2:52-6.

65. Lu LC, Shao YY, Hsu CH, Hsu C, Cheng WF, Lin YL, et al. Metastasectomy of Krukenberg tumors may be associated with survival benefits in patients with metastatic gastric cancer. Anticancer research. 2012;32(8):3397-401.

66. Rosa F, Marrelli D, Morgagni P, Cipollari C, Vittimberga G, Framarini M, et al. Krukenberg Tumors of Gastric Origin: The Rationale of Surgical Resection and Perioperative Treatments in a Multicenter Western Experience. World journal of surgery. 2016;40(4):921-8.

67. McCormick CC, Giuntoli RL, 2nd, Gardner GJ, Schulick RD, Judson K, Ronnett BM, et al. The role of cytoreductive surgery for colon cancer metastatic to the ovary. Gynecologic oncology. 2007;105(3):791-5.

68. Langer B, Bleiberg H, Labianca R, Shepherd L, Nitti D, Marsoni S, et al. Fluorouracil (FU) plus leucovorin (I-LV) versus observation after potentially curative resection of liver or lung metastases from colorectal cancer (CRC): results of the ENG (EORTC/NCIC/CTG/GIVIO) randomized trial. Proc Am Clin Oncol. 2002;21:149a.

69. Portier G, Elias D, Bouche O, Rougier P, Bosset JF, Saric J, et al. Multicenter randomized trial of adjuvant fluorouracil and folinic acid compared with surgery alone after resection of colorectal liver metastases: FFCD ACHBTH AURC 9002 trial. Journal of clinical oncology : official journal of the American Society of Clinical Oncology. 2006;24(31):4976-82.

70. Kim SY, Kim HJ, Hong YS, Jung KH, Park JW, Choi HS, et al. Resected colorectal liver metastases: does the survival differ according to postoperative chemotherapy regimen? Journal of surgical oncology. 2009;100(8):713-8.

71. Sugarbaker PH. Peritoneal Carcinomatosis: Kluwer Academic Publishers, Boston; 1996.

72. Susan D, Reed BG. Elective oophorectomy or ovarian conservation at the time of hysterectomy. In: UpToDate, Post TW (Ed), UpToDate, Waltham, MA(Accessed on 20 January 20 2016). Available from: https://www.uptodate.com/contents /elective-oophorectomy-or-ovarian-conservation-at-the-time-of-hysterectomy.

73. McGill F, Ritter DB, Rickard C, Kaleya RN, Wadler S, Greston WM. Management of Krukenberg tumors: an 11-year experience and review of the literature. Primary care update for Ob/Gyns. 1998;5(4):157-8.

74. Fizazi K, Greco FA, Pavlidis N, Daugaard G, Oien K, Pentheroudakis G, et al. Cancers of unknown primary site: ESMO Clinical Practice Guidelines for diagnosis, treatment and follow-up. Annals of oncology : official journal of the European Society for Medical Oncology. 2015;26 Suppl 5:v133-8.

75. Oien KA. Pathologic evaluation of unknown primary cancer. Seminars in oncology. 2009;36(1): 8-37.

76. Abbruzzese JL, Abbruzzese MC, Lenzi R, Hess KR, Raber MN. Analysis of a diagnostic strategy for patients with suspected tumors of unknown origin. Journal of clinical oncology : official journal of the American Society of Clinical Oncology. 1995;13(8):2094-103.

77. Gross-Goupil M, Massard C, Lesimple T. Identify- 
ing the primary site using gene expression profiling in patients with carcinoma of an unknown

Received 27-8-2018 primary (CUP): a feasibility study from the GEFRevised 10-9-2018 CAPI. Onkologie. 2012;35:54-5. Accepted 22-9-2018 